\title{
INDUTORES DA IMAGEM DE BELO HORIZONTE COMO DESTINO TURÍSTICO: A PERCEPÇÃO DOS RESIDENTES
}

\author{
Valéria Oliveira Bonfim* \\ Marlusa Gosling* \\ Kelly Cristine de Oliveira Meira*** \\ Iury Teixeira de Sevilha Gosling*****
}

RESUMO: O turismo é uma atividade econômica importante, trazendo divisas para os destinos, que buscam tornarem-se competitivos. Nesse contexto, a opinião de residentes sobre as cidades torna-se relevante fonte de informação. O objetivo desse artigo é propor e testar um modelo de fatores teoricamente justificados que influenciam a percepção do morador em termos da imagem de Belo Horizonte, enquanto destino turístico. Para isso, realizou-se uma pesquisa quantitativa (survey) com 185 residentes. A análise de dados apontou que não há diferenças de percepção dos construtos entre homens e mulheres (teste t). Adicionalmente, a regressão linear múltipla apontou que Qualidade da Oferta Turística, os Equipamentos Turísticos e a Infraestrutura Básica foram positivamente relacionados à imagem da cidade.

PALAVRAS-CHAVE: Turismo; Imagem; Percepção dos residentes; Belo Horizonte.

\section{IMAGE PROMOTERS OF BELO HORIZONTE AS A TOURIST SITE: RESIDENTS' PERCEPTION}

ABSTRACT: Tourism is a relevant economic activity, with assets for the sites which, in turn, become competitive. Residents' opinion on cities is an important source of information. Current research proposes and tests a model featuring theoretically justified factors that affect the inhabitants' perception on Belo Horizonte as a tourist site. Survey comprised 185 residents. Data analysis showed that there are no differences between males' and females' construct perceptions (test t). Further, multiple linear regression revealed that Quality of Tourist Demand, Tourist Equipments and Basic Infrastructure were positively related to the city's image.

KEY WORDS: Tourism; Image; residents' perception; Belo Horizonte.

\footnotetext{
Especialista em Gestão Estratégica Universidade Federal de Minas Gerais (UFMG), Brasil.

** Doutora em Administração; Docente Associada na Universidade Federal de Minas Gerais (UFMG); Coordenadora do NEECIM-TUR (Núcleo de Estudos e Estratégias em Comunicação Integrada de Marketing e Turismo) e Coordenadora da Pós-graduação Lato sensu do CEPEAD/FACE/UFMG, Brasil.

*** Universidade Federal de Minas Gerais (UFMG), Brasil.

${ }^{* * * *}$ Universidade Federal de Minas Gerais (UFMG), Brasil.
} 


\section{INTRODUÇÃO}

A pretensão da análise da imagem turística da cidade, pela visão de seus moradores, é fruto da percepção do incremento do turismo no cenário econômico belo-horizontino, assim como também pelo acompanhamento das mudanças ocorridas no setor turístico a partir da prefeitura municipal de Belo Horizonte, pela ação da empresa municipal de turismo de Belo Horizonte (Belotur).

O interesse pelo estudo contempla a existência de uma lacuna no processo de realização do diagnóstico do plano de marketing turístico, o Plano Horizonte, pois não houve preocupação com o público interno - os moradores da cidade. Como o turismo é uma atividade sistêmica, ela depende deste público para ser bem sucedida, portanto, não há como realizar um plano de desenvolvimento bem sucedido sem envolvê-lo. É merecido destacar a importância da participação do morador na realização da atividade turística, já que serão eles próprios os prestadores de serviços que estarão em constante interação com os clientes, que neste caso são os turistas.

A competitividade é definida por Ministério do Turismo (2015, p. 4) como "capacidade crescente de gerar negócios nas atividades econômicas relacionadas com o setor de turismo, de forma sustentável, proporcionando ao turista uma experiência positiva”. No mesmo documento, fruto de uma parceria entre o Ministério do Turismo, o Sebrae Nacional e a FGV (Fundação Getúlio Vargas), Belo Horizonte obteve nível 4 sendo que que os níveis variam de $1=$ pior nível a $5=$ melhor nível. Note-se que Belo Horizonte tem nível superior à média nacional e de cada uma das capitais, além de ter demonstrado estabilidade nos resultados já que desde 2008 está classificado no nível 4 de competitividade (MINISTÉRIO DO TURISMO, 2015).

Tal pesquisa do Ministério do Turismo (2015) avaliou a competitividade dos destinos em termos de 13 dimensões (infraestrutura geral, acesso, serviços e equipamentos turísticos, atrativos turísticos, marketing e promoção do destino, políticas públicas, cooperação regional, monitoramento, economia local, capacidade empresarial, aspectos sociais, aspectos ambientais e aspectos culturais) e mais de 60 variáveis. Entre os resultados obtidos, para Belo Horizonte, destaca-se o fato de que capacidade empresarial, economia local, serviços e equipamentos turísticos, 
marketing e promoção do destino e infraestrutura geral, obtiveram o nível 5 no índice de competitividade e apenas cooperação regional foi classificada no nível 3, sendo as demais dimensões classificadas no nível 4.

Assim, dada a relevância da capital mineira como um destino competitivo, o objetivo desse artigo é propor e testar um modelo de fatores teoricamente justificado que influenciam a imagem da cidade como destino turístico, na ótica dos residentes.

\section{REFERENCIAL TEÓRICO}

\subsection{MARKETING TURÍSTICO}

O mercado competitivo fez com que a atividade turística fosse inserida no consumo de massa e, consequentemente, surgiu a necessidade do turismo se adaptar às novas exigências mercadológicas. Assim, o marketing turístico tornouse um recurso para atingir o objetivo de cada organização presente no sistema de turismo. Petrocchi $(2004$, p. 35) revela que a intenção é que o marketing crie condições favoráveis à toda a coletividade no destino turístico. Note-se que o marketing turístico é derivado do marketing de serviços.

A atividade turística é o resultado da interação de três áreas básicas (PETROCHI, 2004, p. 46): a cadeia produtiva, os setores governamentais e a população. Portanto, o planejamento de marketing deverá contemplar todas estas áreas.

Outro ponto importante ressaltado pelo autor é que o marketing das regiões ou cidades turísticas baseia-se nos desejos e necessidades dos turistas. A partir dessa premissa, entender as suas percepções é imprescindível para projetar e implantar diretrizes e programas de trabalho para manter o lugar sempre competitivo junto aos demais concorrentes. É a adequação da oferta às tendências, que respeita a complexidade da atividade turística e sua gestão, preocupando-se em atender às necessidades dos turistas.

O marketing aplicado ao turismo não poderia ser tratado da mesma forma que o marketing de bens tangíveis, em função das características que diferenciam serviços de produtos, tais como intangibilidade, inseparabilidade da 
produção e consumo, contato com o turista (encontro de serviço), perecibilidade, heterogeneidade, relacionamento baseado nos turistas (PETROCCHI, 2004, p. 43). Acerenza (1991, p. 15) garante que, no marketing turístico, as diferenças ocorrem como consequência das características do produto turístico em particular, sendo agravadas pelo grau de incerteza a que estão expostas as decisões da comercialização do turismo. Além disso, Grisemann e Stockburguer-Sauer (2012) afirmam que o setor do turismo é caracterizado por serviços de alto contato, em que a cocriação de clientes desempenha papel importante. O estudo dos autores contribuiu para o campo da cocriação em marketing e pesquisa em turismo, uma vez que mediu efetivamente o grau real de cocriação dos clientes.

Petrocchi (2004) aponta um fator crucial que reforça a realização do presente estudo, cujo enfoque está na opinião dos residentes de Belo Horizonte, já que o autor sustenta que o marketing do destino turístico deve ser praticado por todas as pessoas, empresas e organizações que o integram.

No contexto específico das pesquisas em turismo, Line e Runyan (2014) argumentam sobre a relevância e função das Organizações de Marketing do Destino (DMOs, do inglês, Destination Marketing Organizations) para a construção da vantagem competitiva sustentada dos destinos turísticos, a partir das teorias da lógica serviço-dominante e da visão baseada em recursos. Os objetivos das DMOs é promover a competitividade sustentada do destino e, para isso, torna-se relevante que os recursos que podem construir a vantagem competitiva sejam cultivados (LINE; RUNYAN, 2014). Para os autores, o desafio das DMOs é facilitar a interação e combinação de recursos com e entre os stakebolders relacionados ao destino.

\subsection{DESTINO TURÍSTICO}

Petrocchi (2004, p. 35) define destino turístico como uma área geográfica que é visitada por turistas e possui limites físicos, políticos e de percepção pelo mercado. Segundo o autor, o destino turístico é caracterizado por uma rigidez da oferta em relação a uma demanda, sendo que esta última é bastante variável. Por isso, ele considera importante que as empresas do setor se resguardem das possíveis oscilações, ao se fortalecerem por meio de parcerias.

A internet se torna a cada dia uma ferramenta indispensável para os 
turistas ao planejarem uma viagem (YE et al., 2010). O aumento da popularidade de plataformas baseadas na web também tem feito com que comentários online de produtos e serviços assumam papel importante no processo decisório do consumidor (ZHANG et al., 2010).

Munar e Jacobsen (2014) afirmam que as mídias sociais são cada vez mais relevantes como parte das práticas de turismo que afetam os destinos e as empresas. Baseados em uma pesquisa no destino turístico em Mallorca, Espanha, Munar e Jacobsen (2014) exploraram as motivações dos usuários que contribuem nas mídias sociais e a vontade daqueles que compartilham o conteúdo por diversos meios sociais. Os resultados fornecem insights sobre os fatores motivacionais, tais como benefícios pessoais e comunitários e o capital social que influencia a partilha de conteúdo gerado pelo usuário. $\mathrm{O}$ estudo revela a predominância de conteúdo visual, juntamente com a relevância das motivações altruístas e comunitárias e as diferenças de motivação entre os tipos de criadores de conteúdo.

Munar e Jacobsen (2014) ressaltam também o grau em que velhas e novas tecnologias se sobrepõem e se complementam. Dispositivos digitais que mediam a visita podem melhorar a qualidade das visitas in loco, individualmente ou de maneira coletiva, através de terminais, tablets, guias de áudio, smartphones, tecnologia 3D e realidade aumentada (JARRIER; BOURGEON-RENAULT, 2012). Organizações que queiram se destacar em relação a seus competidores e que buscam a satisfação de seus clientes precisam estabelecer estratégias para prestarem serviços de qualidade. Ademais, toda a experiência do visitante ao longo da prestação do serviço precisa ser considerada.

Para o melhor entendimento da competitividade dos destinos turísticos, é relevante abordar outro conceito-chave na presente pesquisa, qual seja, a oferta turística.

\subsection{OFERTA TURÍSTICA}

A oferta turística, ou produto turístico, é visto por Acerenza (1991, p. 17) como um amálgama de elementos integrados harmonicamente e que serão ofertados aos turistas. 
No turismo, o produto é um bem ou serviço destinado às necessidades dos turistas. Note-se, porém, que o produto turístico deve ser tratado numa dimensão ampla, pois é influenciado pela geografia, pela infraestrutura, equipamentos, hospitalidade, gastronomia, folclore, serviços urbanos e turísticos, além dos componentes socioculturais de acordo com Beni (1998, p. 153). Dessa forma, a matéria-prima para a oferta turística pode ser concebida como o conjunto dos recursos naturais e culturais, com valores agregados a partir dos serviços complementares.

Beni (1998) ainda destaca a importância de se considerarem as variabilidades da oferta turística, a partir de sua natureza holística e sistêmica que constituem o fenômeno turístico.

A diversidade de serviços e fornecedores torna complexa a gestão integrada da oferta. Os destinos contêm ofertas originárias, em ações isoladas ou gestão integrada da oferta, a partir de ações isoladas ou agrupadas, de múltiplos fornecedores de serviços.

Acerenza (1991, p. 7) mostra que a concepção do produto turístico, como é vista hoje, teve sua origem na Europa Ocidental, no princípio da década de 50 . Petrocchi (2004, p. 74) afirma que a estruturação do produto turístico extrapola o "p" de "produto" do composto de marketing, uma vez que envolve as variáveis: preço e ponto-de-venda, exemplificados pelas agências de viagens. $\mathrm{O}$ autor define produto turístico como composto pelos seguintes elementos: meio natural, meio artificial, meio sociocultural, infraestruturas, cenografia urbana, equipamentos, qualidade dos serviços, hospitalidade, gastronomia, distância entre origem e destino, tipos de pacotes turísticos, eventos e marca.

Segundo Beni (1998), a experiência individual se vincula ao produto final. Isso porque, mesmo se duas pessoas escolham o mesmo destino para uma viagem, cada uma terá um produto, pois para ser o mesmo elas deverão passar pelas mesmas experiências, com os mesmos equipamentos utilizados etc.

Para o entendimento da oferta turística, é imprescindível conhecer os seus componentes: os atrativos turísticos, os equipamentos e serviços turísticos, a infraestrutura básica. 


\subsubsection{Atrativos turísticos}

Acerenza (1991, p. 9) identifica os atrativos turísticos como os principais componentes da oferta turística. São considerados atrativos turísticos todo lugar, objeto, construção ou acontecimento de interesse turístico que motiva o deslocamento de grupos humanos para conhecê-los. Podem ser naturais, históricoculturais; manifestações e usos tradicionais e populares; realizações técnicas e científicas contemporâneas e acontecimentos programados. Esse trabalho enfatizou os atrativos naturais como o parque das Mangabeiras e os histórico-culturais que se encontram dispersos em algumas regiões da cidade de Belo Horizonte.

Do ponto de vista do marketing, Acerenza (1991, p. 9) classifica os atrativos em dois tipos: atrativos de sítio e atrativos de eventos. Os primeiros são resultantes das condições naturais e das atividades humanas da região e que servem de motivação para que turistas visitem o local. Ainda, podem ser segmentados em atrativos naturais, atrativos relativos às manifestações culturais, atrativos relacionados à infraestrutura como, por exemplo, as características gerais das aglomerações urbanas.

Já os atrativos de eventos são os motivos transitórios para a visitação do turista: são as feiras, exposições, congressos, convenções, eventos esportivos, concursos etc.

\subsubsection{Equipamentos e serviços turísticos}

Tais conceitos representam o conjunto de edificações, instalações e serviços indispensáveis ao desenvolvimento da atividade turística, conforme Beni (1998, p. 299). São os meios de hospedagem; alimentação; entretenimento e outros serviços. São essas facilidades que tornam o lugar agradável.

São complementares aos atrativos dos destinos turísticos, pois permitem a permanência e o melhor aproveitamento do lugar.

\subsubsection{Infraestrutura de apoio turístico}

Beni (1998, p. 261) define a infraestrutura de apoio turístico como o conjunto de obras e instalações da estrutura física de base, que criam condições 
para o desenvolvimento de uma unidade turística; são independentes da atividade turística. São as organizações e funções administrativas, sistema de transporte; sistema de comunicações; sistema de segurança; equipamento médico-hospitalar etc.

É um complexo sistema em que a prestação de serviços é a característica fundamental, de acordo com o autor.

\subsection{IMAGEM}

Analisar o termo imagem pode parecer simples; pouco a pouco a sua complexidade é percebida nas tentativas de se responder quais são os elementos que a compõem.

Solha (1999, p. 8) define que a base conceitual para a imagem turística deve ser considerada o amálgama de crenças, ideias, impressões e expectativas de cada indivíduo em relação às localidades turísticas. Para a autora, os elementos componentes da imagem podem ser cognitivos e afetivos. Os primeiros elementos dizem respeito à soma de crenças e de avaliações individuais sobre os atributos do destino. Já os componentes afetivos referem-se aos valores individuais do lugar, baseados nos benefícios que são procurados na viagem. Ainda nesta perspectiva, pode-se dizer que existe uma inter-relação entre essas duas categorias de elementos, que ajudam na formação da imagem que o indivíduo tem do lugar. Note-se que as respostas afetivas a uma localidade turística ocorrem em função do conhecimento que se tem sobre ela.

Nesse ponto, percebe-se que a subjetividade está implícita no processo de construção da imagem. Figueiredo (2001, p. 80) defende que cada indivíduo é diferente do outro e que eles terão diferentes reações pelos seus referenciais e suas experiências particulares.

Uma imagem positiva é um fator importante para a atração de públicos, conforme afirma Figueiredo (2001, p. 79). Para o autor, os benefícios que a imagem pode trazer a uma organização incluem: influenciar o volume de vendas, que poderá ser um atrativo para acionistas e empregados, auxiliar no relacionamento das empresas com a comunidade em geral e com o governo e promover e vender a instituição tal como um produto. 
Por outro lado, a construção inadequada de uma imagem poderá ter resultados catastróficos para localidade, sobretudo pelas especificidades do produto turístico, que diferentemente de outros, só será avaliado durante a experiência da viagem, o que dificulta reverter situações indesejadas.

Conforme Munar e Jacobsen (2014), experiências são pessoais e variam de acordo com que os indivíduos percebem e reagem a lugares e produtos turísticos específicos (destinos, atrações como museus e acomodações). A partilha de experiências inclui os aspectos relacionados ao conhecimento, bem como fatos sobre atributos de férias (preços, condições climáticas, praias e outras atrações), mas, além disso, pode incluir repasse de emoções, imaginações e fantasias. Cidadãos consumidores de entretenimento tendem a se conectar as experiências mais relevantes e que estejam alinhadas com seu estilo de vida e definem determinadas experiências de consumo como representantes de algo mais do que experiências aparentemente comuns de consumo (HILLER, 2011).

Segundo Solha (1999, p. 8), a imagem é um elemento importante, pois é capaz de mensurar a satisfação do turista, além de revelar a sua influência no desenvolvimento turístico de localidades.

Nos dias atuais, com a competitividade gerada pela globalização, até mesmo as cidades procuram traçar suas estratégias de marketing para que a sua imagem seja cada vez mais atrativa e mais vendável. Anand e Servaraj (2013), ao avaliarem a percepção dos clientes, encontraram efeito diretamente positivo da qualidade do serviço na satisfação e, consequentemente, na retenção de clientes. Assim, quanto maior a satisfação, também maior a probabilidade de repetição da visita a um destino (KOZAK, 2001).

\section{METOdOLOGIA}

O desenvolvimento deste estudo realizou-se a partir da necessidade de se conhecer a visão que o residente de Belo Horizonte tem em relação à atividade turística na cidade. Isso porque desde o ano de 2006, a Belotur vem implementando um plano de desenvolvimento de marketing turístico. Como a atividade turística é caracterizada pela sua natureza sistêmica, ao envolver vários setores da economia, 
é de extrema relevância tomar conhecimento da percepção de todos os envolvidos na concretização da atividade. A ênfase da pesquisa é no morador, o cliente interno.

A pesquisa realizada é classificada como conclusiva, por se tratar da análise de relações, examinadas a partir de um processo estruturado, quantitativo. É um tipo de pesquisa para auxiliar no processo de tomada de decisão. O estudo classifica-se como exploratório-descritivo. Segundo Malhotra (2001, p. 107), esse tipo de pesquisa é útil para descrever características do mercado, depende de formulações prévias de hipóteses específicas, é realizada pelos métodos de survey, dados secundários, painéis, dados de observação. $\mathrm{O}$ método de pesquisa utilizado para a obtenção de informações foi o survey, que se baseia no interrogatório dos participantes. As perguntas de um survey devem ser relativas a comportamento, intenções, atitudes, percepção, motivações, e características demográficas e de estilo de acordo com Malhotra (2001, p. 179). O autor destaca o questionário estruturado como o meio mais propício para a realização da coleta de dados, já padronizada. $\mathrm{Ou}$ ainda, pode-se afirmar que o método survey consiste num questionário estruturado aplicado a uma determinada amostra de uma população e destinado a colher informações específicas dos entrevistados.

Uma vez que os dados primários serão as principais fontes norteadoras para a conclusão desse estudo, é válido justificar a escolha pelo método survey em função de suas vantagens a serem destacadas: aplicação simples; confiabilidade nas respostas, já que o questionário é estruturado; e a facilidade para a codificação, análise e interpretação dos dados.

Ainda pode-se caracterizar a pesquisa como um estudo transversal, o que significa dizer que a coleta dos dados é realizada em uma única vez.

O questionário (Quadro 1) foi aplicado pessoalmente e individualmente. Em relação à amostragem, que foi classificada como por conveniência, o número de respondentes que colaboraram para este estudo foi de 185 respondentes, todos residentes em Belo Horizonte.

Nota-se que os respondentes deveriam explicitar sua percepção a respeito de cada aspecto (isto é, cada variável) evidenciado nas afirmativas do questionário (Quadro 1). Para isso, deveriam classificar as afirmativas por níveis de percepção. Estes níveis foram identificados em escalas Likert, que variaram de 1 a 5, sendo $1=$ péssimo até $5=$ ótimo, para as afirmativas dos construtos qualidade da oferta turística (QOFT), condições da oferta turística (CONDOF), qualidade dos equipamentos e 
serviços turísticos (EST), qualidade da infraestrutura básica (INFBAS) e qualidade da infraestrutura administrativa (INFADM). Para se mensurar a percepção de imagem, foi feita apenas uma única afirmativa, na qual o respondente deveria mostrar seu grau de concordância, sendo $1=$ Discordo Totalmente até $5=$ Concordo Totalmente.

Quadro 1. Questionário de pesquisa

(continua)

Qualidade da oferta turística (QOFT)

Como o Sr. (a) classificaria a qualidade da oferta turística de BH? (1 = péssimo até 5 = ótimo $)$

QOFT1 - Roteiro Marcos da Modernidade (Pontos turísticos: Igreja de São Francisco de Assis, Casa do Baile, Museu de Arte da Pampulha, Mineirão, Zoológico e Parque Ecológico da Pampulha)

QOFT2 - Roteiro Sínteses de Minas (Ponto turístico: Mercado Central)

QOFT3 - Roteiro BH: Passado e Presente (Pontos turísticos: Conjunto Arquitetônico da Praça da Liberdade, Museu de Mineralogia, Museu Mineiro, Antiquários e Savassi)

QOFT4 - Roteiro Ofícios de Minas (Pontos turísticos: Palácio das Artes, Conjunto Arquitetônico da Avenida Afonso Pena, Conservatório de Música da UFMG, Instituto Moreira Salles, Centro de Cultura de Belo Horizonte, Centro Cultural da UFMG, Museu de Artes e Ofícios, Parque Municipal e Feira de Arte e Artesanato nos domingos)

QOFT5 - Roteiro Vida ao Ar Livre (Pontos turísticos: Bares e botecos)

QOFT6 - Roteiro Horizontes da Cidade (Pontos turísticos: Praça do Papa, Parque das Mangabeiras, Mirante, Rua do Amendoim)

Condições da oferta turística (CONDOFT)

No conjunto dos roteiros citados, classifique quanto: $(1=$ péssimo até $5=$ ótimo $)$

CONDOFT1 - O estado de conservação e limpeza nos pontos turísticos de Belo Horizonte, é...

CONDOFT2 - A acessibilidade (facilidade e qualidade dos meios de transporte e acesso) para visitar os atrativos é:

CONDOFT3 - A divulgação dos pontos turísticos é...

CONDOFT14 - O preço cobrado para o acesso aos pontos turísticos é...

CONDOFT5 - O conhecimento que tenho dos atrativos turísticos da minha cidade é...

Equipamentos e serviços turísticos (EST)

: $(1$ = péssimo até $5=$ ótimo $)$

EST1 - Meios de hospedagem (hotéis, pousadas, albergues, imóveis / aluguel)

EST2 - Alimentação: restaurantes, lanchonetes, sorveterias, cafés

EST3 - Agências de turismo: agências emissivas e receptivas

EST4 - Transporte Turístico: rodoviário, aluguel de carros 
(continua)

\begin{tabular}{|l|}
\hline EST5 - Entretenimentos: boates, bares, cervejarias \\
\hline EST6 - Eventos: centro de convenções, área de exposições e feiras \\
\hline EST7 - Parques, jardins e praças \\
\hline EST8 - Área de eventos culturais (cinemas, teatros, casas de espetáculos) \\
\hline EST9 - Espaços para eventos esportivos (ginásios, estádios) \\
\hline EST10 - Comércio turístico (souvenirs, artesanato, produtos típicos) \\
\hline EST11 - Centros de informação turística: \\
\hline $\begin{array}{l}\text { Infraestrutura Básica (INFBAS) } \\
\text { De acordo com a qualidade da infraestrutura disponível no município, classifique: (1 = péssimo } \\
\text { até } 5 \text { = ótimo) }\end{array}$ \\
\hline INFBAS1 - Infraestrutura de acesso: rodovias \\
\hline INFBAS2 - Saneamento: captação, tratamento e despejo de esgotos \\
\hline INFBAS3 - Energia: produção e distribuição de energia elétrica, distribuição de gás \\
\hline INFBAS4 - Comunicações: telefonia fixa e móvel, rádio, televisão, correios, jornais e revistas \\
\hline INFBAS5 - Vias urbanas de circulação: implantação, conservação e sinalização \\
\hline INFBAS6 - Controle de poluição: ar, água, som, visual \\
\hline $\begin{array}{l}\text { Infraestrutura Administrativa (INFADM) } \\
\text { De acordo com a qualidade da infraestrutura administrativa disponível no município, que nota o } \\
\text { Sr.(a) daria para cada um deles na escala: (1 = péssimo até } 5 \text { = ótimo) }\end{array}$ \\
\hline INFADM1 - Transportes: táxi, ônibus \\
\hline INFADM2 - Serviços Bancários: agências bancárias, caixas eletrônicos, serviços de câmbio \\
\hline INFADM3 - Serviços de limpeza pública: coleta e tratamento do lixo \\
\hline $\begin{array}{l}\text { INFADM4 - Serviços de Saúde: Farmácias, Pronto Socorro, Hospitais, laboratórios de análises } \\
\text { clínicas }\end{array}$ \\
\hline INFADM5 - Serviços de segurança: Polícia Turística, serviços de Salva-vidas, Polícia Militar, Civil \\
\hline $\begin{array}{l}\text { INFADM6 - Serviços de informação: Postos de informaçoes e sinalização urbana e turística, Mapas } \\
\text { e guias locais }\end{array}$ \\
\hline $\begin{array}{l}\text { INFADM7 - Serviços de telecomunicações: postos telefônicos, orelhões, rádio e televisão fax, } \\
\text { internet, correios }\end{array}$ \\
\hline $\begin{array}{l}\text { INFADM8 - Serviços de apoio a automobilistas: postos de combustíveis, oficinas mecânicas, } \\
\text { borracheiros, oficinas peças }\end{array}$ \\
\hline INFADM9 - Comércio turístico: lojas de conveniências, de artesanato, de produtos típicos \\
\hline
\end{tabular}


(conclusão)

INFADM10 - Sistema Judiciário: delegacia de polícia, delegacia do turista, consumidor

IMAGEM - De modo geral, BH é uma ótima cidade para os turistas? $(1=$ Discordo Totalmente a 5 $=$ concordo totalmente)

Fonte: Elaborado pelos autores

Após a realização desta etapa de coleta de dados, foi utilizado o software SPSS 10.0 for the Windows para fornecer as estatísticas necessárias para a análise dos construtos.

O método de análise aplicado no estudo foi o de regressão múltipla, com o objetivo de determinar quais variáveis independentes explicariam uma variação significativa na variável dependente de interesse, a estrutura e a forma da relação existente, sua intensidade e valores da variável dependente.

A análise de regressão múltipla, conforme Malhotra (2001, p. 464), é uma técnica estatística que desenvolve simultaneamente uma relação matemática entre variáveis independentes e uma variável dependente escalonada por intervalo.

Nesta pesquisa, os construtos qualidade da oferta turística, condições da oferta turística, qualidade da infraestrutura básica, qualidade dos equipamentos e serviços turísticos e qualidade da infraestrutura administrativa foram transformados em escores médios. Os escores foram, assim, as variáveis independentes da regressão cuja variável dependente foi a imagem.

Com a coleta e análise de dados, foi possível discutir as percepções dos moradores de Belo Horizonte, que, em termos gerenciais, poderão ser consideradas para a execução de um planejamento de marketing turístico para Belo Horizonte. $\mathrm{O}$ resultado deste trabalho de pesquisa deve ser verificado como uma tendência, mas não como uma certeza, em termos de generalização, uma vez que a amostragem não foi probabilística.

\subsection{MODELO DE PESQUISA}

O modelo foi elaborado a partir da definição de Beni (1998, p. 42) que ao considerar a natureza sistêmica das atividades envolvidas no turismo, criou o modelo referencial denominado Sistema de Turismo (Sistur). Dessa forma, ele retrata a atividade turística numa localidade por meio da interação da oferta turística, das condições em que ela se apresenta aos turistas, e os equipamentos e serviços 
turísticos. Para o funcionamento da atividade turística é preciso o complemento a partir da inclusão da infraestrutura básica e da infraestrutura administrativa, como retrata a Figura 1:

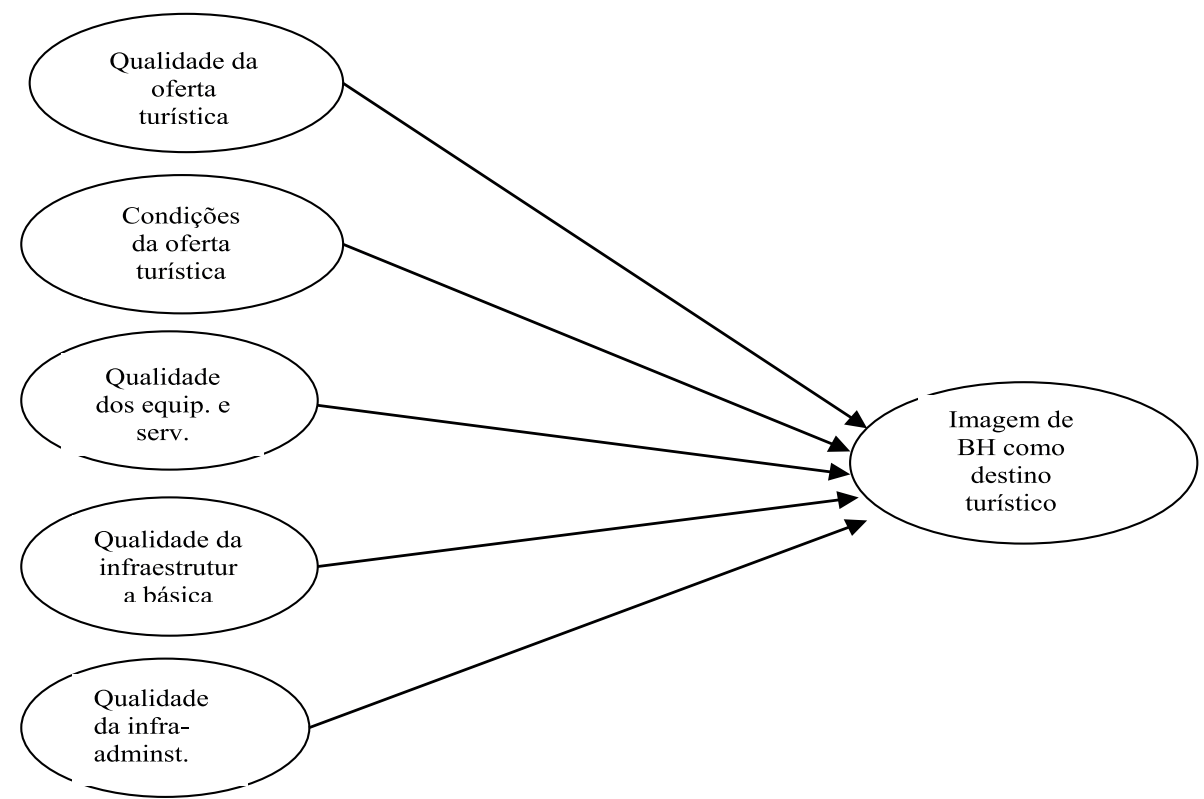

Figura 1. Modelo de pesquisa

Fonte: Elaborado pelos autores

As hipóteses de pesquisa derivada do modelo são as seguintes: $\mathrm{H} 1=\mathrm{a}$ qualidade da oferta turística impacta positivamente a imagem de Belo Horizonte como uma cidade turística; $\mathrm{H} 2=$ as condições da oferta turística impactam positivamente a imagem da cidade como um destino turístico; $\mathrm{H} 3=$ a qualidade da infraestrutura de equipamentos e serviços turísticos influencia a imagem de Belo Horizonte como um destino turístico; $\mathrm{H} 4=$ a qualidade da infraestrutura básica impacta positivamente a imagem de Belo Horizonte como um destino turístico; H5 $=\mathrm{a}$ qualidade da infraestrutura administrativa impacta positivamente a imagem de Belo Horizonte como um destino turístico.

\section{ANÁLISE DOS DADOS}

O ponto de partida para a avaliação dos dados coletados foi a análise da 
confiabilidade dos construtos. Segundo Malhotra (2001), a confiabilidade dos construtos diz respeito à possibilidade de se repetir o estudo e obter resultados semelhantes, mostrando a consistência das escalas do questionário. Assim, o autor explica que em estudos exploratórios e descritivos, o valor mínimo aceitável para o Alfa de Cronbach, índice que mede a confiabilidade simples dos construtos, deve ser 0,60. Hair et al. (2006) concordam com Malhotra (2001) sobre tal limite para estudos exploratórios.

O construto Qualidade da Oferta Turística (QOFT) apresentou um resultado considerado confiável, uma vez que o Alpha de Cronbach é equivalente a 0,7856.

O construto Condições da Oferta Turística (Condof) apresentou um resultado considerado confiável, uma vez que o Alpha de Cronbach foi superior a 0,6 , sendo, portanto um resultado confiável.

No construto Qualidade dos Equipamentos e Serviços Turísticos (EST) foi necessário proceder a retirada das variáveis EST 7 e EST 9, pois comprometiam o resultado de confiabilidade. Após as retiradas dessas variáveis da análise, a confiabilidade do construto foi elevada para o valor 0,8579 .

A confiabilidade do construto Qualidade da Infraestrutura Básica (INFBAS) estava pouco satisfatória, por uma de suas variáveis. Portanto, foi necessário excluíla para que se obtivesse um índice de confiabilidade superior. Antes da retirada da variável IFBAS4 o Alfa de Cronbach era 0,7874.

Por fim, a análise do construto Infraestrutura Administrativa (INFADM) mostrou um índice de confiabilidade pouco satisfatório, inferior a 0,6 , sendo que a exclusão de variáveis não melhorou esse valor. Portanto, nas análises subsequentes, tal construto será retirado, dado que não apresentou confiabilidade.

Para a continuidade da análise de dados, a partir dos resultados do Alfa de Cronbach, os construtos foram transformados em uma variável, pelas médias de seus respectivos itens remanescentes, ou seja, cada construto transformou-se em uma variável.

Para a análise foram considerados 185 respondentes. No comparativo dos dados acima, constata-se consistência nas respostas dadas, isto é, pouca variabilidade, uma vez que os desvios-padrão são relativamente baixos. Por outro lado, percebe-se que as pessoas avaliaram bem os aspectos tratados no questionário, visto que de 1 a 5, as médias foram altas (acima de 3), sendo que o construto que foi pior avaliado foi a infraestrutura básica, cuja média foi 3,1492 e o melhor avaliado foi qualidade da oferta turística, com média de 4,0649. 
Tabela 1. Descritivas dos construtos

\begin{tabular}{lccccc}
\hline \multicolumn{7}{c}{ Descriptive Statistics } \\
\hline & N & Minimum & Maximum & Mean & $\begin{array}{c}\text { Std. } \\
\text { Deviation }\end{array}$ \\
\hline QOFT & 185 & 2,00 & 5,00 & 4,0649 &, 5893 \\
CONDOF & 185 & 1,00 & 5,00 & 3,1503 &, 6462 \\
EST & 185 & 2,00 & 4,89 & 3,6913 &, 5873 \\
INFBAS & 185 & 1,40 & 5,00 & 3,1492 &, 6927 \\
Valid N (listwise) & 185 & & & & \\
\hline
\end{tabular}

Fonte: Saída do Software SPSS

A partir disso, foram feitos testes estatísticos para se verificar se havia diferença de percepção de cada um dos construtos, de acordo com o sexo do respondente. Nesse caso, o teste feito foi o teste de diferença de médias, isto é, o teste $t$. Os resultados se encontram na Tabela 1 , sendo que na coluna da variável sexo, o valor 1 representa as médias dos respondentes do sexo Feminino e o valor 2 representa as médias dos respondentes do sexo Masculino. Ao se observarem os valores das médias dos dois grupos (sexo $=1$ e sexo $=2$ ), pode-se perceber que em geral as mulheres têm percepções ligeiramente maiores que as dos homens, para os construtos pesquisados. No entanto, essa estatística descritiva (média) deve ser submetida a um teste de hipótese, para que se verifique se tal diferença é estatisticamente significativa. Assim, para o teste t, a hipótese nula é "não há diferença de percepção entre homens e mulheres" e se o valor da significância do teste t for maior que, usualmente, $5 \%$ (isto é, 0,05 ), não se rejeita a hipótese nula. Nesse caso, se sig $>0,05$, não terá havido diferença estatisticamente significativa de percepção entre os grupos.

Note-se que na Tabela 2, a coluna do valor de significância do teste $\mathrm{t}$ que todos os valores são acima de 0,05 , a testando, pois, que não há diferença estatisticamente significativa entre as percepções entre homens e mulheres, acerca da qualidade da oferta turística, das condições da oferta turística, da qualidade dos equipamentos e serviços turísticos e da infraestrutura básica. 


\begin{tabular}{|c|c|c|c|c|c|c|c|c|c|}
\hline 节 & 产 & $\tilde{n}$ & $\tilde{\sigma}$ & 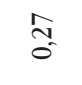 & $\stackrel{n}{\tilde{\sigma}}$ & ֶิ & ָิ & $\underset{\tilde{\sigma}}{\tilde{\sigma}}$ & $\stackrel{\overbrace{}}{0}$ \\
\hline 苞 & : & 8 & 8 & $\begin{array}{l}\circ \\
\frac{1}{9}\end{array}$ & $\stackrel{0}{\circ}$ & $\frac{2}{0}$ & $\stackrel{0}{\stackrel{2}{c}}$ & $\stackrel{\infty}{\stackrel{\infty}{6}}$ & $\stackrel{\infty}{\stackrel{\infty}{c}}$ \\
\hline 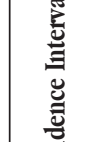 & 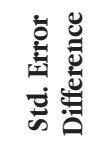 & Oे & Oे & $\stackrel{0}{\stackrel{1}{0}}$ & $\stackrel{0}{\circ}$ & ప్ & ठ․ & $\stackrel{0}{\circ}$ & $\stackrel{0}{\circ}$ \\
\hline 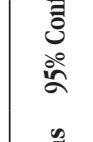 & 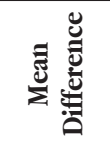 & $\stackrel{-}{\sigma}$ & $\vec{\sigma}$ & $\underset{0}{\infty}$ & $\underset{0}{\infty}$ & 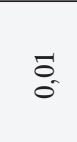 & 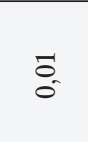 & $\stackrel{\tilde{f}}{\xi}$ & $\stackrel{\approx}{*}$ \\
\hline 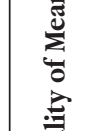 & 的兽 & $\underset{0}{8}$ & \&. & हे & हु & ڤิ & ๙ิ & 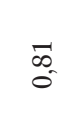 & $\begin{array}{l}\vec{\infty} \\
0\end{array}$ \\
\hline 矛 & 岁 & $\begin{array}{l}8 \\
\approx \\
\infty\end{array}$ & $\begin{array}{l}n \\
\hat{\alpha} \\
\infty\end{array}$ & $\begin{array}{l}8 \\
\infty \\
\infty\end{array}$ & $\begin{array}{l}\hat{N} \\
\text { â } \\
0\end{array}$ & $\begin{array}{l}8 \\
\approx \\
\infty\end{array}$ & $\begin{array}{l}\overrightarrow{5} \\
-\infty \\
0\end{array}$ & 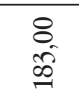 & $\begin{array}{l}8 \\
\infty \\
\infty \\
0 \\
0\end{array}$ \\
\hline 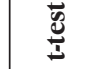 & 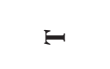 & $\widetilde{\sigma}$ & $\approx$ & $\begin{array}{l}\infty \\
\infty \\
0\end{array}$ & $\stackrel{\infty}{\infty}$ & 忨 & $\stackrel{+r}{0}$ & $\underset{\sim}{\tilde{o}}$ & $\stackrel{\text { d }}{\sigma}$ \\
\hline & $\stackrel{\infty}{\infty}$ & $\frac{R}{0}$ & & $\stackrel{\text { fo }}{0}$ & & $\tilde{\sigma}$ & & ô & \\
\hline 퓔 & 口 & $\frac{1}{0}$ & & $\hat{n}$ & & 亏े & & o. & \\
\hline 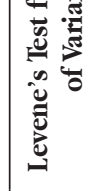 & & 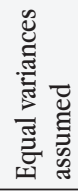 & 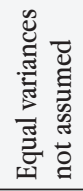 & 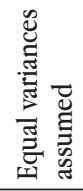 & 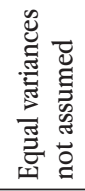 & 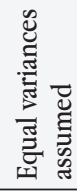 & 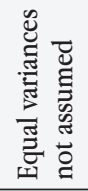 & 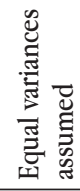 & 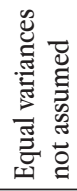 \\
\hline & 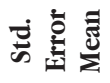 & $\stackrel{8}{8}$ & $\stackrel{8}{\circ}$ & $\stackrel{1}{0}$ & 용 & $\stackrel{0}{8}$ & 8 & bo & 10 \\
\hline & 造 & $\stackrel{2}{0}$ & $\stackrel{\bar{\sigma}}{0}$ & $\underset{0}{0}$ & $\underset{0}{0}$ & ర్ర & in & Oे & $\frac{R}{0}$ \\
\hline . & $\stackrel{\Xi}{\Xi}$ & $\stackrel{n}{\stackrel{f}{*}}$ & के & $\frac{a}{n}$ & $\Rightarrow$ & $\vec{r}$ & $\underset{\sigma}{\tilde{\sigma}}$ & $\underset{r}{\stackrel{0}{n}}$ & $\frac{ \pm}{n}$ \\
\hline$\hat{z}$ & $z$ & ๙ૂ & $\approx \alpha$ & $\approx$ & $\approx$ & $\approx$ & $\approx$ & $\approx$ & $\widetilde{\alpha}$ \\
\hline (b) & 离 & $\neg$ & N & - & v & - & $\sim$ & - & $\sim$ \\
\hline & 总 & \multicolumn{2}{|c|}{ 동 } & \multicolumn{2}{|c|}{ 岁 } & \multicolumn{2}{|c|}{ E } & \multicolumn{2}{|c|}{$\begin{array}{l}\text { 令 } \\
\text { 至 }\end{array}$} \\
\hline
\end{tabular}




\section{ANÁLISE DO MODELO PROPOSTO}

No Quadro 1, estão descritos os construtos que compõem o modelo para o conhecimento da imagem do potencial turístico de Belo Horizonte a partir de seu público interno, os moradores da cidade.

Para testar o modelo proposto, como já mencionado na metodologia, optou-se por fazer uma regressão linear múltipla, sendo Imagem $(\mathrm{BH})$ a variável dependente e as variáveis independentes foram os construtos que tiveram confiabilidade atestada, isto é, Qualidade da Oferta Turística (QOFT), Condições da Oferta Turística (Condof), Qualidade dos Equipamentos e Serviços Turísticos (EST) e Qualidade da Infraestrutura Básica (INFBAS).

Quadro 1. Variáveis consideradas no método de regressão

\begin{tabular}{|l|l|l|ll|}
\hline \multicolumn{5}{|c|}{ Variables Entered/Removed $^{\text {b }}$} \\
\hline Model & Variables entered & Variables removed & Method & \\
\hline 1 & INFAS, QOFT, & & & Enter \\
& CONDOF, EST & & & \\
\hline
\end{tabular}

a All requested variables entered.

b Dependent variable: BH

Fonte: Saída do Software SPSS

A Tabela 3 registra a associação linear entre as variáveis independentes. A intensidade de associação é medida pelo $\mathrm{R}^{2}$, que representa a proporção da variação na variável dependente, imagem de Belo Horizonte como destino turístico, explicada pelas variáveis independentes. Portanto, nesse estudo, a qualidade da oferta turística, as condições da oferta turística, os equipamentos turísticos e a infraestrutura básica explicaram 33,1\% da imagem de vocação turística que o morador de Belo Horizonte percebe que a cidade tem.

Tabela 3. Associação entre as variáveis

\begin{tabular}{llllr}
\hline \multicolumn{5}{c}{ Model summary $^{\mathrm{b}}$} \\
\hline Model & $\mathrm{R}$ & $\mathrm{R}$ Square & Adjusted R Square & Std. Error of the estimative \\
\hline 1 &, $575^{\mathrm{a}}$ &, 331 &, 316 &, 8060 \\
\hline a Predictors: (Constant), INFBAS, QOFT, CONDOF, EST & & \\
b Dependent variable: BH \\
Fonte: Saída do software SPSS
\end{tabular}


Tabela 4. Análise da variância

\begin{tabular}{rlrrrrr}
\hline \multicolumn{7}{c}{ ANOVA $^{\mathrm{b}}$} \\
\hline \multirow{2}{*}{ Model } & & $\begin{array}{c}\text { Sum of } \\
\text { squares }\end{array}$ & \multicolumn{1}{c}{ df } & $\begin{array}{c}\text { Mean } \\
\text { square }\end{array}$ & \multicolumn{1}{c}{ F } & Sig. \\
\hline 1 & Regression & 57,787 & 4 & 14,447 & 22,236 &, $000^{\mathrm{a}}$ \\
\hline & Residual & 116,948 & 180 &, 650 & & \\
\hline & Total & 174,735 & 184 & & & \\
\hline
\end{tabular}

a Predictors: (Constant), INFBAS, QOFT, CONDOF, EST

b Dependent variable: $\mathrm{BH}$

Fonte: Saída do Software SPSS

Tabela 6. Coeficientes

\begin{tabular}{|c|c|c|c|c|c|c|c|c|}
\hline \multicolumn{9}{|c|}{ Coefficients $^{\mathrm{a}}$} \\
\hline \multirow[b]{2}{*}{ Model } & & \multicolumn{2}{|c|}{$\begin{array}{l}\text { Unstandardized } \\
\text { Coefficients }\end{array}$} & \multirow{2}{*}{$\begin{array}{c}\begin{array}{c}\text { Standardiz } \\
\text { ed } \\
\text { Coefficients }\end{array} \\
\text { Beta }\end{array}$} & \multirow[b]{2}{*}{$\mathbf{t}$} & \multirow[b]{2}{*}{ Sig. } & \multicolumn{2}{|c|}{$\begin{array}{l}\text { Collinearity } \\
\text { statistics }\end{array}$} \\
\hline & & B & $\begin{array}{l}\text { Std. } \\
\text { Error }\end{array}$ & & & & Tolerance & VIF \\
\hline \multirow[t]{5}{*}{1} & (Constant) &,- 977 &, 494 & & $-1,979$ &, 049 & & \\
\hline & QOFT & ,348 & ,110 & ,210 & 3,154 &, 002 & ,836 & 1,197 \\
\hline & CONDOF & ,218 & ,118 & , 145 & 1,846 & 0,67 & 606 & 1,650 \\
\hline & EST & ,258 & ,132 & ,155 & 1,955 &, 052 & ,589 & 1,697 \\
\hline & INFBAS & , 409 & ,094 & ,290 & 4,345 &, 000 & ,832 & 1,202 \\
\hline
\end{tabular}

a Dependent variable: $\mathrm{BH}$

Fonte: Saída do Software SPSS

Os coeficientes de todas as variáveis foram positivos indicando que avaliações mais altas de cada um dos fatores significativos conduzem para aumentar a percepção da imagem turística para a cidade.

Os resultados indicaram que nem todos os fatores dos critérios de escolha foram significativos na explicação da imagem percebida pelos moradores de Belo Horizonte. O teste feito foi o teste t. Para que não se aceite a hipótese nula de que os coeficientes da regressão são estatisticamente iguais a 0 , o valor de SIG deve ser 
menor que 5\% (isto é, 0,05 ). Sendo assim, o construto Condições da Oferta Turística ultrapassou o parâmetro que permitiria que ele continuasse no modelo (sig foi de $0,67$, isto é, maior que 0,05$)$. É válido destacar que a retirada do construto, atende intenção de encontrar o menor número de variáveis independentes e que sejam relevantes na determinação da variável dependente, com a maior precisão possível. Por outro lado, o SIG do construto Qualidade da Oferta Turística, cujo SIG foi de 0,052, foi mantido, já que o valor do SIG ficou muito próximo ao valor de corte.

A partir dessa análise estatística, foi possível estimar o valor dos construtos escolhidos para retratar a imagem que o morador de Belo Horizonte possui da cidade, sob a perspectiva de um destino turístico. Para se chegar neste resultado, foi estabelecida uma relação que pode ser compreendida pelo modelo a seguir;

Imagem Qual. da oferta turística + Qual. dos equip. e serviços turísticos + Qual. da infraestrutura básica

Figura 2. Modelo de definição da imagem turística de BH na perspectiva dos moradores

Fonte: Dados da pesquisa

Confirma-se a partir da realização deste levantamento estatístico que o retrato do turismo em Belo Horizonte, na ótica do morador, depende linearmente da qualidade percebida na oferta turística, por meio dos atrativos turísticos, acrescido da análise qualitativa da infraestrutura básica e da qualidade dos equipamentos e serviços turísticos apresentados no município.

Portanto, a equação que definirá o modelo de pesquisa é:

$$
\begin{aligned}
& \text { Imagem }=\beta 0+\beta 1 . \text { QOFT }+\beta 2 \cdot \mathrm{EST}+\beta 3 \mathrm{INFBAS} \\
& \text { Imagem }=-0,977+0,348 \mathrm{QOFT}+0,258 \mathrm{EST}+0,409 \mathrm{INFBAS}
\end{aligned}
$$

Esta equação é capaz de prever o posicionamento dos moradores de Belo Horizonte, em função da atividade turística existente nesta cidade. Adicionalmente, percebe-se, a partir da análise dos coeficientes da equação, que a infraestrutura básica é o que mais impacta a percepção do belo-horizontino sobre a vocação turística da cidade (imagem). Portanto, é por meio destes minuciosos sinais de percepção que o planejamento de marketing deverá ser aperfeiçoado, a fim de viabilizar o 
planejamento da cidade como um destino turístico, e assim criar estratégias de marketing pelo conhecimento das variáveis que realmente influenciam a percepção da imagem turística da cidade pelos moradores.

\section{CONSIDERAÇÕES FINAIS}

Pelos dados apresentados, aufere-se que a contribuição deste estudo acadêmico foi a de agregar valor ao plano de desenvolvimento de marketing turístico para Belo Horizonte. Verifica-se também que o objetivo proposto foi alcançado, uma vez que ficou definido o modelo que determina o que os moradores consideram importante para Belo Horizonte se transformar num ícone para o turismo.

Vale, ainda, destacar o modelo proposto, a partir das hipóteses que o compunham. As hipóteses que previam (1) impacto positivo da Qualidade da Oferta Turística na Imagem de BH como destino turístico; (2) impacto positivo da Qualidade dos Equipamentos Turísticos na Imagem de BH como destino turístico e (3) impacto positivo da Infraestrutura Básica na Imagem de $\mathrm{BH}$ como destino turístico; foram todas confirmadas. Por outro lado, a hipótese que previa (1) impacto positivo da Infraestrutura Administrativa na Imagem de $\mathrm{BH}$ como destino turístico não foi sequer testado, visto que o construto não apresentou confiabilidade e, portanto, foi retirado do modelo. Além disso, a hipótese que previa impacto positivo das Condições da Oferta Turística na Imagem de BH como destino turístico foi refutada, já que o coeficiente desse construto, na equação de regressão, foi estatisticamente igual a 0 .

Uma limitação do presente trabalho foi o fato da amostragem ter sido por conveniência. Isso limita a generalização dos resultados encontrados, sem, no entanto, invalidá-los. A partir dos resultados, pode ser um bom indicativo que, se o poder público e/ou os investimentos privados quiserem que os belo-horizontinos considerem BH como cidade turística, deverão investir nessas áreas, que têm impacto positivo na sua percepção.

Espera-se que a cidade seja posicionada no contexto do turismo nacional e internacional, conforme as metas da Empresa Municipal de Turismo de Belo 
Horizonte. Ademais, esta pesquisa possui a funcionalidade de viabilizar e aperfeiçoar o planejamento e a gestão do marketing turístico, a partir do conhecimento dos fatores que realmente influenciam a percepção da imagem turística da cidade pelos moradores.

Seria interessante a transformação do morador em um agente de marketing turístico. Por meio da propaganda de boca-a-boca, ele poderá motivar as pessoas com que têm relacionamento como, por exemplo, amigos, colegas de trabalho e parentes a vir conhecer a localidade. Assim também será importante realizar campanhas em escolas a fim de despertar o interesse por fazer turismo na própria cidade, valorizando a oferta turística. É preciso despertar nos belo-horizontinos o desejo de se construir uma marca forte para a cidade.

As sugestões de melhorias que poderão ser realizadas no plano de marketing é o aprimoramento dos produtos turísticos oferecidos, com a ampliação da divulgação do que a cidade oferece.

Em relação aos equipamentos e serviços turísticos, acredita-se que a capacitação de jovens para atuar no mercado turístico, com uma nova mentalidade, a de que é possível transformar a cidade em uma referência para o turismo.

Ressalta-se que estudos futuros poderão adicionar outros construtos, teoricamente alicerçados, ao modelo. Isso poderá aumentar a percepção do morador sobre a imagem de Belo Horizonte como destino turístico.

\section{REFERÊNCIAS}

ACERENZA, M. À. Promoção turística: um enfoque metodológico. São Paulo: Pioneira, 1991.

ANAND, S. V.; SELVARAJ, M. Evaluation of service quality and its impact on customer satisfaction in indian banking sector: a comparative study using SERVPERF. Life Science Journal, v. 10, n. 1, p. 3267-3274, 2013.

BENI, M. C. Análise estrutural do turismo. 2. ed. São Paulo: SENAC, 1998.

FIGUEIREDO, M. P. de. Imagens de um Belo Horizonte: o turismo como uma 
estratégia de desenvolvimento local. 2001. Dissertação (Mestrado em Administração) - Universidade Federal de Minas Gerais, 2001.

MINISTÉRIO DO TURISMO. Índice de competitividade do turismo nacional: relatório Brasil 2015. Brasília, 2015, 92p. Disponível em < http://belohorizonte. mg.gov.br/sites/belohorizonte.pbh.gov.br/files/anexos/belotur/relatorio_ brasil_2015_65_destinos_intudores.pdf > . Acesso em: abril 2017.

GRISEMANN, U. S.; STOKBURGER-SAUER, N. E. Customer co-creation of travel services: The role of company support and customer satisfaction with the co-creation performance. Tourism Management, n. 33, p. 1483-1492, 2012.

HAIR, J. F.; BLACK, W. C.; BABIN, B. J.; ANDERSON, R. E.; TATHAM, R. L. Multivariate data analysis. [s.l.]: Prentice Hall Pearson Education, 2006

HILLER, M. Uma experiência estética e de marketing em museus. 2011. Disponível em: <http:// faculdadefundetec.com.br/img/revista_academica/pdf/ artigo_hiller.pdf > . Acesso em: 30 de junho de 2016.

JARRIER, E.; BOURGEON-RENAULT, D. Impact of mediation devices on the museum visit experience and on visitor's behavioural intentions. International Journal of Arts Management, v. 15, n. 1, p. 18-29, 2012.

KOZAK, M. Repeaters' behaviour at two distinct destinations. Annals of Tourism Research, v. 28, n. 3, p. 784-807, 2001.

LINE, N. D.; RUNYAN, R. C. Destination marketing and the service-dominant logic: A resource-based operationalization of strategic marketing assets. Tourism Management, n. 43, p. 91-102, 2014.

MALHOTRA, N. Pesquisa de marketing: uma orientação aplicada. 3. ed. Porto Alegre: Bookman, 2001.

MUNAR, A. M.; JACOBSEN, J. K. S. Motivations for sharing tourism experiences through social media. Tourism Management, n. 43, p. 46-54, 2014. 
PETROCCHI, M. Marketing para destinos turísticos. São Paulo: Futura, 2004.

SOLHA, K. T. Divulgação de imagens turísticas: o exemplo de Porto Seguro (Bahia). 1999. Dissertação (Mestrado em Ciências) - Universidade de São Paulo, 1999.

YE, Q.; LAW, R.; GU, B. The impact of online user reviews on hotel room sales. International Journal of Hospitality Management, n. 28, p.180-182, 2010.

ZHANG, Z.; YE, Q.; LAW, R.; LI, Y. The impact of e-word-of-mouth on the online popularity of restaurants: A comparison of consumer reviews and editor reviews. International Journal of Hospitality Management, v. 29, p. 694-700, 2010.

Recebido em:08 de fevereiro de 2017 Aceito em:17 de abril de 2017 